\title{
Estudo do comportamento no estado fresco e endurecido de argamassa com escória de aciaria BSSF
}

\author{
Study of the behavior in the fresh and hardened \\ state of mortar with BSSFsteel slag
}

Felipe Alves Amancio ${ }^{1}$, Alisson Rodrigues de Oliveira Dias ${ }^{1}$, Douglas Alexandre Lima ${ }^{2}$, Antônio Eduardo Bezerra Cabral ${ }^{1}$

\begin{abstract}
${ }^{1}$ Programa de Pós-Graduação em Engenharia Civil - Estruturas e Construção Civil, Universidade Federal do Ceará, PEC/UFC, Acesso Público, bloco 733, Campus do Pici, CEP: 60455-900, Fortaleza, CE, Brasil

${ }^{2}$ Departamento de Estruturas e Construção Civil, Universidade Federal do Ceará, Acesso Público, bloco 733, Campus do Pici, CEP: 60455-900, Fortaleza, CE, Brasil

e-mail: douglas.edif@gmail.com, felipeaamancio@hotmail.com,rodrigues_alisson@live.com, eduardo.cabral@ufc.br.
\end{abstract}

\section{RESUMO}

Em 2017, a produção de aço bruto no Brasil foi de 34,4 milhões de toneladas, o que representa um crescimento de 9,8\% em comparação com 2016. Apesar da importância econômica para a economia do país, a indústria siderúrgica representa um grande problema ambiental, em virtude da quantidade de escórias geradas no processo de produção do aço. Neste sentido, o presente trabalho teve por objetivo investigar as propriedades das argamassas de revestimento produzidas com escória de aciaria Baosteel Slag Short Flow (BSSF) em substituição à areia natural. $\mathrm{O}$ traço investigado foi de 1:1:6 (cimento: cal: agregado), com a substituição em volume nos teores de $0 \%, 20 \%, 40 \%, 60 \%$ e $80 \%$. Os ensaios realizados foram: índice de consistência, densidade, teor de ar incorporado, squeeze-flow, resistências à compressão axial e à tração na flexão, módulo de elasticidade dinâmico, absorção por capilaridade, índice de vazios, e resistência potencial de aderência à tração. Constatou-se que para um índice de consistência de $260 \pm 5 \mathrm{~mm}$, as argamassas com escória de aciaria BSSF apresentaram uma maior relação a/c, além de maior densidade de massa aparente nos estados fresco e endurecido, módulo de elasticidade dinâmico, coeficiente de capilaridade e índice de vazios. A argamassa de referência apresentou ainda retenção de água e resistência potencial de aderência superiores aos das argamassas com escória de aciaria BSSF, enquanto que os valores de resistência à compressão e as propriedades físicas foram similares. Cabe destacar ainda o aumento significativo no módulo de elasticidade dinâmico nas argamassas com escória de aciaria, em virtude da elevada massa especifica da escória, o que podem prejudicar a durabilidade do revestimento, em virtude da redução da capacidade de absorver deformações.

Palavras-chave: Escória de aciaria BSSF. Resistência potencial de aderência a tração. Durabilidade. Argamassa de revestimento.

\section{ABSTRACT}

In 2017, crude steel production in Brazil was 34.4 million tons, which represents a growth of $9.8 \%$ compared to 2016. Despite the economic importance for the country's economy, the steel industry represents a major environmental problem, due to the amount of slag generated in the steel production process. In this sense, the present study aimed to investigate the properties of mortars produced with Baosteel Slag Short Flow (BSSF) steel slag to replace natural sand. The mix investigated was 1:1:6 (cement:lime:aggregate), with volume substitution at $0 \%, 20 \%, 40 \%, 60 \%$ and $80 \%$. The tests were: consistency index, density, incorporated air content, squeeze-flow, compressive and flexural strength, dynamic modulus of elasticity, capillary absorption, void index, and potential tensile bond strength. It can be seen that for a consistency index of $260 \pm 5 \mathrm{~mm}$, the mortars with BSSF steel slag showed a higher w/c ratio, in addition to higher density of apparent mass in the fresh and hardened state, dynamic modulus of elasticity, capillarity coefficient, void index. The reference mortar also presented water retention and potential adhesion resistance higher than the mortars with BSSF steel slag, while the values of compressive strength and physical properties were similar. It is also worth mentioning the significant increase in the dynamic elasticity modulus in mortars with BSSF steel slag, due to the high specific mass of the slag, which can harm the durability of the coating, due to the reduction of the capacity to absorb deformations.

Keywords: BSSF steel slag. Potential tensile bond strength. Durability. coating mortar. 


\section{INTRODUÇÃO}

A produção mundial de aço, em 2017 alcançou novo recorde, ao totalizar 1,689 bilhões de toneladas [1]. No Brasil, está produção foi na ordem de 34,4 milhões de toneladas, ocupando a $9^{\circ}$ posição na produção mundial. A indústria metalúrgica, apesar do seu papel de extrema importância na economia, produz grandes quantidades de subprodutos, entre eles, as escórias, que representam um problema para a fábrica e para o meio ambiente [2]. Dentre os subprodutos, a escória de aciaria é responsável por $28 \%$ dessa geração, ou seja, 5,5 milhões de toneladas/ano. A principal destinação dessas escórias tem sido para venda à indústria cimenteira (37\%) e reutilização interna (26\%), onde tem sido utilizada para composição de bases e sub-bases de pavimentos e nivelamento de terrenos e aterros [3] (IABr, 2016).

Devido a essa problemática, a Baosteel, uma empresa siderúrgica chinesa, com sede em Xangai, desenvolveu um novo tratamento para as escórias de aciaria. No processo de granulação da BSSF, a escória líquida produzida é transferida para um tambor de granulação, onde ela é tratada com água injetada com um tempo de permanência entre três e cinco minutos, o que reduz representativamente a quantidade de cal livre que não reagiu [4].

Durante a geração da escória de aciaria Baosteel Slag Short Flow (BSSF), seu resfriamento se dá através do uso de jatos de água, juntamente com forças mecânicas para trituração, formando um material de característica vítrea, granulado e com baixas quantidades de cal livre $[4,5]$. Com esse processo produz-se uma escória livre de expansão [5, 6].

Como resultado desse processo tem-se a obtenção da escória de aciaria do tipo BSSF, objeto de estudo deste trabalho. No Ocidente, a Companhia Siderúrgica do Pecém - CSP, localizada no Estado do Ceará Brasil, é a única empresa siderúrgica que incluiu esse processo na sua linha de produção do aço até o presente momento. Com isto, existem poucos trabalhos quanto a empregabilidade desta escória em argamassas de revestimento, tendo apenas publicações com a utilização de escórias de aciaria obtidas pelos métodos tradicionais, os quais foram utilizados nas discussões dos resultados.

Nesse contexto, o setor da construção civil consiste em uma das indústrias mais interessadas no aproveitamento desse tipo de resíduo e na busca de materiais de construção de menor custo e impacto ambiental reduzido. A busca pelo uso de materiais alternativos aumentou de forma importante com a crescente conscientização sobre a importância das questões ambientais e a busca por novas soluções que combinam crescimento econômico e preservação do patrimônio natural $[7,8]$.

Aliado a isto, a exploração de recursos naturais, a exemplo da areia empregada na produção de argamassas e concretos, causa inúmeros danos ao meio ambiente, como desmatamento e remoção do solo [9]. Além da possibilidade de geração de tais impactos, a disponibilidade de agregados naturais com propriedades satisfatórias para serem empregados na construção civil tem se tornado crítica em muitas áreas urbanas.

Neste sentido, vem crescendo as pesquisas relacionadas ao aproveitamento de agregados alternativos em compósitos cimentícios tem crescido cada vez mais, com destaque para a areia de britagem [10, 11], borracha de pneu [12], resíduo de vidro [13, 14], resíduos de rochas ornamentais [15], lodo de tratamento de água [16] e de esgoto [17].

Portanto, faz-se necessário buscar o aproveitamento do subproduto da indústria siderúrgica no setor da construção civil, obtendo-se assim, redução nos custos dos produtos da construção, além de reduzir os danos ambientais gerados pelo consumo e extração exacerbados de areia na produção de argamassas e concretos. Neste sentido, o presente trabalho visa analisar as propriedades das argamassas de revestimento no estado fresco e endurecido, com a substituição em volume da areia por escória de aciaria BSSF nas proporções de $0 \%, 20 \%, 40 \%, 60 \%$ e $80 \%$ no traço 1:1:6 (cimento: cal: agregado).

\section{MATERIAIS E MÉTODOS}

\subsection{Materiais}

A cal utilizada foi do tipo hidratada CH-I. O cimento foi CP V, com as propriedades físicas e químicas do descritas na Tabela 1. 
Tabela 1: Características físicas e químicas do cimento Portland CP V

\begin{tabular}{l|l|l|l|l}
\hline Propriedade Químicas & Norma & Unid & Resultado & $\begin{array}{l}\text { Especificação - Norma } \\
\text { NBR 16697:2018 }\end{array}$ \\
\hline Perda ao fogo & NM 18/12 & $\%$ & 4,39 & $\leq 6,5$ \\
\hline Óxido de magnésio $-\mathrm{MgO}$ & $\mathrm{NM} \mathrm{11-2/12}$ & $\%$ & 4,17 & $\leq 6,5$ \\
\hline Anidrido sulfúrico $-\mathrm{SO}_{3}$ & $\mathrm{NM} \mathrm{16/12}$ & $\%$ & 3,24 & $\leq 3,5$ \\
\hline Resíduo insolúvel & $\mathrm{NM} \mathrm{15/12}$ & $\%$ & 0,69 & $\leq 3,5$ \\
\hline Anidrido carbônico - $\mathrm{CO}_{2}$ & $11583 / 91$ & $\%$ & 2,97 & $\leq 5,5$ \\
\hline \multirow{2}{*}{ Propriedades Físicas } & Norma & Unid & Resultado & $\begin{array}{l}\text { Especificação - Norma } \\
\text { NBR 16697:2018 }\end{array}$ \\
\hline Finura (\#200) & NBR 11579/12 & $\%$ & 0,20 & $\leq 6,0 \%$ \\
\hline \multirow{3}{*}{ Resistência à compressão $(\mathrm{MPa})$} & $\begin{array}{l}\text { NBR 7215/1996 } \\
1 \text { dias }\end{array}$ & $\mathrm{MPa}$ & 25,9 & $\geq 14,0 \mathrm{MPa}$ \\
\cline { 2 - 6 } & 3 dias & $\mathrm{MPa}$ & 36,6 & $\geq 24,0 \mathrm{MPa}$ \\
\cline { 2 - 5 } & 7 dias & $\mathrm{MPa}$ & 44,3 & $\geq 34,0 \mathrm{MPa}$ \\
\hline
\end{tabular}

A escória utilizada neste estudo foi proveniente da Companhia Siderúrgica do Pecém, localizada no Estado do Ceará, Brasil. A escória foi seca em estufa a $105 \pm 5^{\circ} \mathrm{C}$ e realizado o peneiramento, conforme estabelece a NBR NM 248 (ABNT, 2003) [18]. Foi realizado o ajuste da granulometria da escória de aciaria. Este procedimento ocorreu da seguinte forma, primeiramente foi realizado a granulometria da areia natural, e em seguida enquadrou-se a escória de aciaria BSSF na mesma curva, a fim de igualar a distribuição granulométrica da areia natural, evitando influência do tamanho dos grãos na trabalhabilidade e demais propriedades das argamassas, sendo investigada apenas o efeito da substituição do grão. A Figura 1 apresenta a distribuição granulométrica dos agregados miúdos, enquanto que as características físicas são apresentadas na Tabela 2. Nota-se que se classificam na zona utilizável e um pequeno trecho na Zona ótima, conforme NBR 7211 (ABNT, 2009) [19].

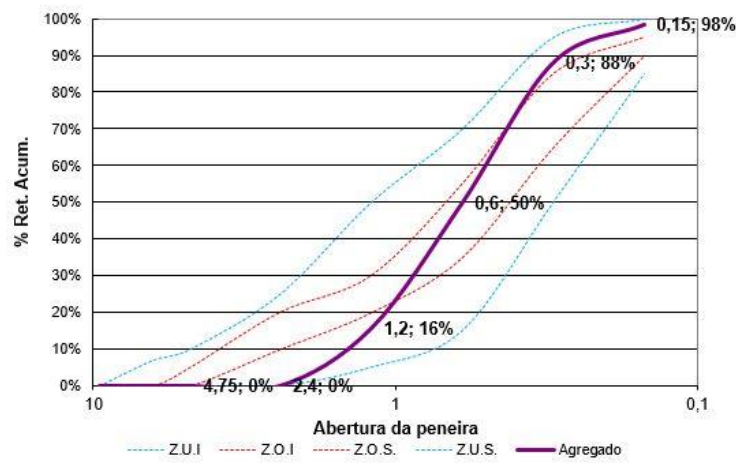

Figura 1: Curva granulométrica dos agregados

Tabela 2: Propriedades físicas dos agregados miúdos.

\begin{tabular}{l|l|l|l|l}
\hline ENSAIO & NORMA & UNIDADE & AREIA NATURAL & ESCÓRIA \\
\hline Dimensão máxima & NBR NM 248 (ABNT,2003) [18] & $\mathrm{mm}$ & 2,36 & 2,36 \\
\hline Módulo de finura & NBR NM 248(ABNT, 2003) [18] & - & 2,52 & 2,52 \\
\hline Massa unitária & NBR NM 45 (ABNT, 2006) [20] & $\mathrm{g} / \mathrm{cm}^{3}$ & 1,41 & 2,08 \\
\hline Absorção de água & NBR NM 52 (ABNT, 2009) [21] & $\%$ & 1,3 & 2,1 \\
\hline Massa específica & NBR NM 52 (ABNT, 2009) [21] & $\mathrm{g} / \mathrm{cm}^{3}$ & 2,59 & 3,62 \\
\hline
\end{tabular}

Foi verificada a forma dos grãos dos agregados por meio do Aggregate Image Measurement System (AIMS), realizado no Laboratório de Mecânica dos Pavimentos - LMP da Universidade Federal do Ceará UFC. Este ensaio realiza a classificação da forma dos agregados, por meio de parâmetros de forma $2 \mathrm{D}$ e angularidade para agregados miúdos; e angularidade, textura superficial, lamelaridade e esfericidade para agregados graúdos. Foi possível verificar que a areia natural tende a apresentar partículas mais arredondadas que a escória de aciaria BSSF, além de textura mais polida, ao passo que a escória de aciaria apresentou textura com baixa rugosidade, conforme a classificação de Al Rousan (2004) [22]. A Figura 2 apresenta a amostra de areia natural e escória de aciaria BSSF. 


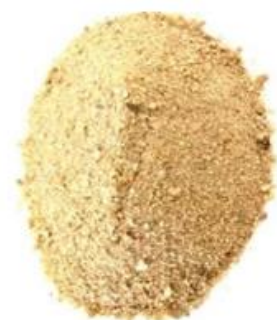

a)

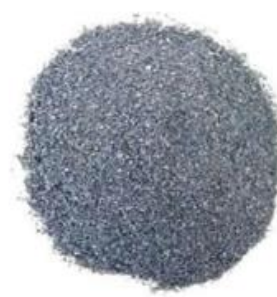

b)

Figura 2: Identificação dos agregados miúdos a) areia natural e b) escória de aciaria BSSF

Em relação à caracterização química da escória de aciaria BSSF, foi realizado a fluorescência de raioX (FRX) em um espectrômetro de raios-X Rigaku ZSX mini II, do Laboratório de Raios X da UFC. Os resultados estão na Tabela 3, os quais mostraram que a escória é constituída basicamente de $\mathrm{Fe}_{2} \mathrm{O}_{3}$ e $\mathrm{CaO}(>88 \%)$.

Tabela 3: Composição química da escória de aciaria BSSF

\begin{tabular}{lllllllllll}
\hline Óxidos & $\mathrm{Al}_{2} \mathrm{O}_{3}$ & $\mathrm{SiO}_{2}$ & $\mathrm{P}_{2} \mathrm{O}_{5}$ & $\mathrm{~K}_{2} \mathrm{O}$ & $\mathrm{CaO}$ & $\mathrm{TiO}_{2}$ & $\mathrm{Cr}_{2} \mathrm{O}_{3}$ & $\mathrm{MnO}$ & $\mathrm{Fe}_{2} \mathrm{O}_{3}$ & $\mathrm{Co}_{2} \mathrm{O}_{3}$ \\
\hline Amostra (\%) & 0,63 & 5,84 & 1,01 & 0,04 & 33,46 & 0,63 & 0,21 & 5,09 & 52,98 & 0,12 \\
\hline
\end{tabular}

No que se refere à composição mineralógica da escória de aciaria BSSF, esta foi analisada por meio de difração de raio-X, realizado no Laboratório de Raios-X do Departamento de Física da Universidade Federal do Ceará - UFC. O equipamento utilizado foi o difratômetro para amostras policristalinas modelo Xpert Pro MPD Panalytical. A amostra utilizada neste ensaio foi passante na peneira 200, abertura da malha de $75 \mu \mathrm{m}$. A amostra foi distribuída num substrato de silício monocristalino, cuja superfície de pó foi o mais plano possível. A radiação utilizada foi de cobalto (Kalfa1) monocromatizado por um conjunto formado de dois cristais de germânio e um espelho parabólico. Nessa análise foi possível identificar principalmente, a presença das fases cristalinas de wustita $(\mathrm{FeO})$ e magnetita $\left(\mathrm{Fe}_{3} \mathrm{O}_{4}\right)$ (Figura 3).

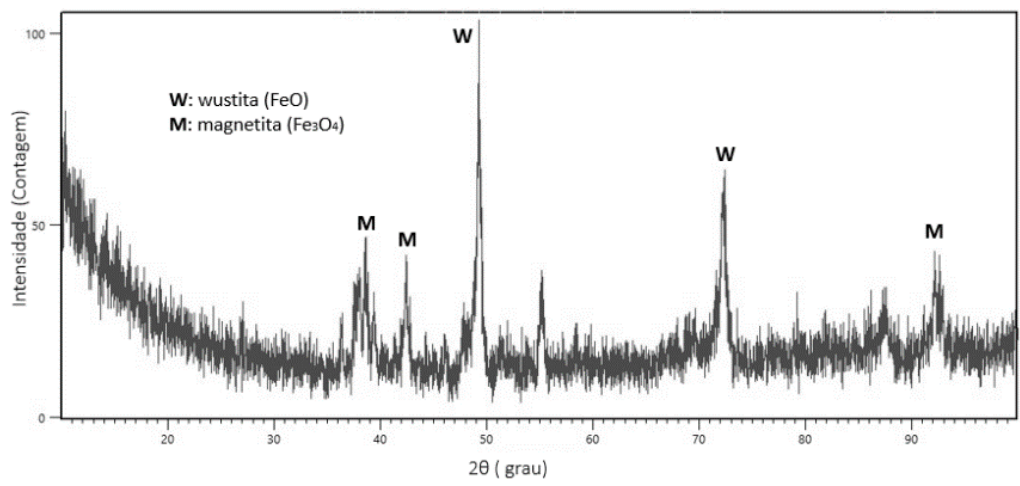

Figura 3: Difratograma da escória de aciaria BSSF.

Apesar do difratograma apresentar um certo halo amorfo, com os ensaios de determinação do índice de atividade pozolânica, realizados conforme a NBR 5752 (ABNT, 2014) [23], foi possível determinar um índice de atividade pozolânica de 71\%, o qual, conforme a norma ABNT NBR 12653 [24] não caracteriza a escória de aciaria BSSF como material pozolânico, pois o valor obtido é inferior ao estabelecido (maior ou igual a 90\%). Ademais, ainda conforme as demais exigências da NBR 12653 indicam que o material não é pozolânico.

Utilizou-se um equipamento com radiação de cobalto monocromatizada. Apesar das intensidades baixas, por volta de 50 a 100, estas não comprometem a identificação das fases. Em adição, tem-se que as intensidades altas, aumentaria demasiadamente o tempo de contagem. Como a amostra apresentava ferro na composição, não é recomendado radiação de cobre, pois assim, aumenta-se muito a intensidade do background, comprometendo assim a identificação das fases.

Foi investigado ainda a expansibilidade da escória BSSF com base no ensaio de determinação da expansibilidade do cimento pelo método de Le Chatelier, conforme NBR 11582 (ABNT, 2016) [25]. A escória 
de aciaria BSSF não apresentou expansão a frio e em relação à expansão a quente, os valores obtidos foram na ordem de $1,16 \mathrm{~mm}$, encontrando-se dentro do limite máximo especificado de $5 \mathrm{~mm}$ pela ABNT NBR 16697 (2018).

A amostra de escória de aciaria BSSF utilizada foi passante na peneira 200, a qual foi obtida por meio de triturador mecânico. Para esse método foi adotado um teor de substituição de cimento por escória de aciaria BSSF de 50\%, em volume. Para MEHTA, 1999 apud MASUERO, 2001 [26], esse teor é suficiente para que o fenômeno ocorra, caso o material possua características expansivas. Destaca-se que a mesma não apresentou expansão a frio e em relação à expansão a quente, todos os resultados obtidos foram inferiores a $5 \mathrm{~mm}$.

\subsection{Métodos de pesquisa}

As argamassas foram preparadas de acordo com a NBR 16541 (ABNT, 2016) [27]. A substituição da areia natural por escória foi realizada em volume, por meio das massas específicas, nos teores de $0 \%, 20 \%, 40 \%$, $60 \%$ e $80 \%$ de substituição. Os traços unitários e o consumo de materiais por $\mathrm{m}^{3}$ estão apresentados na Tabela 4.

A substituição da areia por escória de aciaria foi dada em volume, conforme a equação 1 , sendo $\mathrm{m}$ (a massa do material) e $\gamma$ (massa específica do material). Essa substituição se fez necessário para que os traços tivessem a mesma quantidade de cimento por $\mathrm{m}^{3}$, e assim comparar os resultados com o traço de referência (ARG0).

$$
M_{\text {escória }}=M_{\text {areia }} \frac{\gamma_{\text {escória }}}{\gamma_{\text {areia }}}
$$

Tabela 4: Traços utilizados na pesquisa.

\begin{tabular}{|c|c|c|c|c|c|c|c|c|c|c|}
\hline \multicolumn{6}{|c|}{ TRAÇO UNITÁRIO EM MASSA } & \multicolumn{5}{|c|}{ CONSUMO DE MATERIAL POR $\mathbf{M}^{3}$} \\
\hline TRAÇO & $\begin{array}{l}\text { TEOR } \\
\text { (\%) }\end{array}$ & $\begin{array}{l}\text { CIMENTO } \\
\text { (KG) }\end{array}$ & $\begin{array}{l}\text { CAL } \\
\text { (KG) }\end{array}$ & $\begin{array}{l}\text { AREIA } \\
\text { (KG) }\end{array}$ & $\begin{array}{l}\text { ESCÓRIA } \\
\text { (KG) }\end{array}$ & $\begin{array}{l}\text { CIMENTO } \\
\text { (KG) }\end{array}$ & $\begin{array}{l}\text { CAL } \\
\text { (KG) }\end{array}$ & $\begin{array}{l}\text { AREIA } \\
\text { (KG) }\end{array}$ & $\begin{array}{l}\text { ESCÓRIA } \\
\text { (KG) }\end{array}$ & $\begin{array}{l}\text { ÁGUA } \\
\text { (KG) }\end{array}$ \\
\hline ARG0 & 0 & 1,0 & 0,4 & 4,70 & 0,00 & 296,8 & 118,7 & 1395,2 & 0,0 & 317,9 \\
\hline ARG20 & 20 & 1,0 & 0,4 & 3,8 & 1,3 & 296,0 & 118,4 & 1112,9 & 387,7 & 320,2 \\
\hline ARG40 & 40 & 1,0 & 0,4 & 2,8 & 2,6 & 295,1 & 118,1 & 832,3 & 776,2 & 321,7 \\
\hline ARG60 & 60 & 1,0 & 0,4 & 1,9 & 3,9 & 293,6 & 117,4 & 551,9 & 1156,7 & 325,6 \\
\hline ARG80 & 80 & 1,0 & 0,4 & 0,9 & 5,7 & 292,1 & 116,9 & 274,6 & 1536,7 & 328,4 \\
\hline
\end{tabular}

A consistência foi determinada por meio do ensaio da mesa de consistência (flow table), no qual foi obtida a quantidade de água para se obter um espalhamento de $260 \pm 5 \mathrm{~mm}$, conforme NBR 13276 (ABNT, 2016) [28]. Após a fixação da relação a/c, as argamassas foram produzidas para analisar as demais propriedades no estado fresco.

A determinação da densidade foi realizada pelo método gravimétrico, conforme a NBR 13278 (ABNT, 2005) [29] logo após a mistura. O teor de ar incorporado foi calculado a partir da densidade, quantidade de água e massa específica dos materiais. A retenção de água das argamassas foi determinada conforme prescreve a NBR 13277 (ABNT, 2005) [30], aplicando-se uma sucção de 51 mmHg durante 15 minutos na argamassa. Por fim, para investigar o comportamento reológico das argamassas, foi realizado o squeeze-flow, estabelecido pela NBR 15839 (ABNT, 2010) [31], o qual foi utilizado uma célula de carga de $2 \mathrm{kN}$, o ensaio foi realizado no intervalo de tempo de 10 minutos após a mistura, a uma velocidade de $3,0 \mathrm{~mm} / \mathrm{s}$. Sendo o ensaio finalizado quando a amostra apresentar um deslocamento máximo de $9 \mathrm{~mm}$ ou carga máxima de $1 \mathrm{kN}$, o que ocorrer primeiro.

No ensaio do squeeze flow, foi identificado ainda as fases do comportamente. Conforme Cardoso; $\mathrm{Pi}$ leggi John (2005) [32] explicam que o resultado do squeeze-flow é uma curva carga versus deslocamento, dividido em 3 estágios, conforme Figura 4 


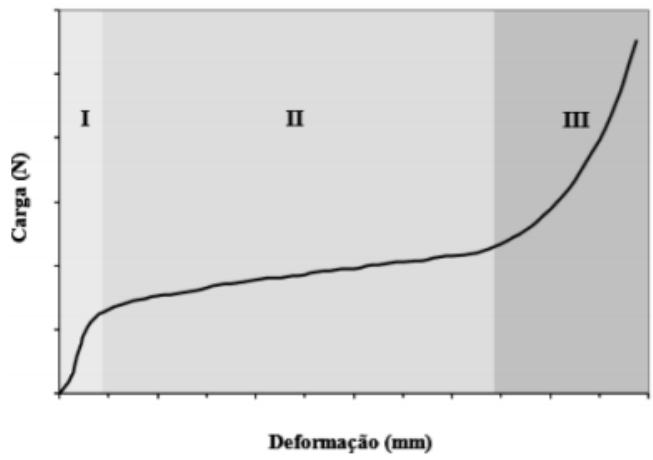

Figura 4: Perfil típico de carga vs. deslocamento de um ensaio de squeeze-flow. Fonte: CARDOSO et al.(2005)

Conforme Cardoso et al.(2005) [32] explicam que no estágio I (pequenas deformações) o material comporta-se como um sólido, apresentando deformação elástica linear. Uma argamassa que apresente comportamento com uma parcela significativa nesse estágio, possivelmente apresentará problemas de fissuração ainda no estado fresco devido à recuperação elástica após a retirada do esforço (após a passagem da desempenadeira). No estágio II (deslocamentos intermediários) à compressão resulta em deformações radial elongacional e de cisalhamento. O material flui por deformação plástica e/ou viscosa dependendo das suas características constitutivas. Nesta etapa, o material é capaz de sofrer grandes deformações sem aumento significativo da força necessária para o deslocamento, o que aparenta ser um comportamento apropriado para aplicação e espalhamento de argamassas [32].

Por fim, no estágio III, o material é submetido a grandes deformações. Pode ocorrer um aumento exponencial da carga necessária para o deslocamento da argamassa. Devido à aproximação das partículas dos materiais constituintes, as deformações geram forças restritivas 29 ao fluxo. Este estágio relaciona-se com os procedimentos de aplicação e acabamento da argamassa devem ser dificultados, devido às altas cargas necessárias para deformá-lo, possivelmente levando a um acabamento defeituoso [32].

Em relação aos ensaios no estado endurecido, foram todos realizados aos 28 dias. Foram moldados corpos de prova prismáticos de dimensões $40 \mathrm{~mm}$ x $40 \mathrm{~mm}$ x $160 \mathrm{~mm}$ para o ensaio de resistência à compressão e à tração, módulo de elasticidade dinâmico (considerando o coeficiente de Poisson 0,20), densidade aparente e absorção de água por capilaridade, respectivamente estabelecidos pelas NBR 13279 (ABNT, 2005) [33], NBR 15630 (ABNT, 2008) [34], NBR 13280 (ABNT, 2005) [35], e NBR 15259 (ABNT, 2005) [36], sendo 3 corpos de prova para cada ensaio.

Para o ensaio de módulo de elasticidade dinâmico (Ed), foram realizadas 3 determinações em corpos de provas distintos. Primeiramente, determinou-se a velocidade de propagação ultrassônica (VPU) por meio do equipamento Pundit Lab+, com frequência dos transdutores na ordem de $54 \mathrm{~Hz}$, conforme Equação 2, sendo L a distância entre os pontos de acoplamento dos transdutores (comprimentos do corpo de prova, em $\mathrm{mm}$ ) e $\mathrm{t}-\mathrm{o}$ tempo registrado pelo mostrador digital, em $\mu \mathrm{s}$.

$$
V=\frac{L}{t}
$$

Em seguida. O módulo de elasticidade dinâmico foi determinado conforme Equação 3.

$$
E d=\rho \cdot v^{2} \cdot \frac{(1+\mu) \cdot(1-2 \mu)}{1-\mu}
$$

Sendo:

$\rho$ - densidade de massa aparente no estado endurecido da argamasssa $\left(\mathrm{kg} / \mathrm{m}^{3}\right)$

$\mathrm{v}$ - velocidade de propagação ultrassônica $(\mathrm{mm} / \mu \mathrm{s})$

$\mu$ - coeficiente de poisson, sendo usualmente 0,20 nesta equação.

Foram moldados ainda corpos de prova cilíndricos de $5 \mathrm{~cm}$ de diâmetro por $10 \mathrm{~cm}$ de altura para os ensaios de índice de vazios, absorção de água e massa específica, conforme NBR 9778 (ABNT, 2005) [37]. Por fim, foram confeccionados painéis de bloco cerâmico com ranhuras ao ar livre, os quais foram umedecidos e logo em seguida foi realizado o preparo da base com aplicação manual de chapisco com consistência fluida no traço em volume de 1:3 (cimento CP V e areia grossa seca, com módulo de finura 3,02), no intuito de melhorar a aderência do revestimento. Após 7 dias de cura do chapisco, foram revestidos com os traços em estudos nas dimensões $50 \mathrm{~cm}$ x $50 \mathrm{~cm}$ x 2,5 cm, executados de forma manual, e com o mesmo profissional que executou o chapisco, levando aproximadamente 1 h e $30 \mathrm{~min}$ para executar os painéis. Após 28 dias foram realizados os ensaios de aderência, conforme preconiza a NBR 13528 (ABNT, 2010) [38]. 
Por fim, para a análise e tratamento dos dados se deu por meio da Análise de Variância (ANOVA) e Teste de Tukey, por meio do software Statistic 7.0. Inicialmente, determinou-se os resíduos padronizados e eliminação dos dados espúrios, sendo considerados dados espúrios aqueles com valor excedente a um valor de referência de $\pm 1,96$ nos resíduos padronizados, a fim de que se tivesse um nível de confiança de $95 \%$ ou nível de significância de 0,05 .

\section{RESULTADOS E DISCUSSÕES}

\subsection{Estado fresco}

A Tabela 5, apresenta a caracterização das argamassas quanto as propriedades no estado fresco.

Tabela 5: Propriedades no estado Fresco.

\begin{tabular}{l|l|l|l|l|l|l}
\hline & $\begin{array}{c}\text { Teor de } \\
\text { água } \\
(\mathbf{\%})\end{array}$ & $\begin{array}{c}\text { Relação } \\
\mathbf{a} / \mathbf{c}\end{array}$ & $\begin{array}{c}\text { Índice de } \\
\text { consistência } \\
(\mathbf{m m})\end{array}$ & $\begin{array}{c}\text { Densidade de } \\
\text { massa }\left(\mathbf{k g} / \mathbf{m}^{3}\right)\end{array}$ & $\begin{array}{c}\text { Teor de ar } \\
\text { incorporado } \\
(\%)\end{array}$ & $\begin{array}{c}\text { Retenção de } \\
\text { água }(\%)\end{array}$ \\
\hline ARG0 & 14,9 & 1,071 & 257 & 2048 & 4 & 91 \\
\hline ARG20 & 14,3 & 1,082 & 261 & 2142 & 4 & 84 \\
\hline ARG40 & 13,7 & 1,090 & 263 & 2220 & 5 & 81 \\
\hline ARG60 & 13,3 & 1,109 & 263 & 2323 & 5 & 81 \\
\hline ARG80 & 12,9 & 1,124 & 259 & 2452 & 4 & 83 \\
\hline
\end{tabular}

As argamassas com escória de aciaria BSSF apresentaram relação a/c superior à da argamassa convencional, produzida apenas com areia natural, para obter o espalhamento fixado em $260 \pm 5 \mathrm{~mm}$, conforme NBR 13276 (ABNT, 2005) [28]. Isto se deve a maior absorção de água da escória (Tabela 2), em comparação a areia natural, bem como a forma dos grãos (conforme análise dos grãos realizado pelo AIMS). Estudo realizado por LE; SHEEN; BUI (2017) [39] com escória de aciaria diferente da BSSF, constataram que o aumento do teor de substituição do agregado natural por escória ocasiona uma menor fluidez nas argamassas no estado plástico, o que pode vir a interferir na determinação da relação a/c pelo ensaio flow table. Os autores alegam que esse fato é causado pela textura da superfície áspera e pela forma angular da escória de aciaria, se comparada com a forma cúbica do agregado natural.

Em relação à densidade das argamassas no estado fresco, houve crescimento representativo com o aumento do teor de substituição de areia por escória, atingindo um aumento de quase $20 \%$ em entre os traços ARG0 e ARG80. O aumento se deve as características dos materiais, tendo em vista que a massa específica da escória é maior que a da areia [40-42].

Quanto ao teor de ar, nota-se que esta propriedade não foi afetada pela substituição da areia natural pela escória de aciaria. Cabe citar que os valores são baixos, na ordem de $4 \%$ a $5 \%$ devido à não utilização de aditivos. Para argamassas de revestimento produzidas sem aditivos, sejam argamassas simples ou mistas, o teor de ar geralmente encontra-se em torno de 2 a $5 \%$ do volume total [43]. Este valor corresponde ao ar aprisionado, cujas bolhas de ar são irregulares e não estáveis, resultante do aprisionamento durante a mistura, enquanto que o ar incorporado é composto por bolhas de ar estáveis com aspecto de esferas microscópicas, resultante do uso de aditivos [43].

Em relação a retenção de água, nota-se que houve uma redução desta propriedade com o aumento do teor de substituição. Isto se deve possivelmente em virtude da maior relação a/c das argamassas com escória, pois conforme [44], a argamassa se torna menos retentora de água quando a proporção de água:aglomerante é aumentada.

A Figura 5 apresenta os resultados obtidos pela ensaio do squeeze-flow. Constata-se que para o teor de água definido conforme o índice de consistência fixado em $260 \pm 5 \mathrm{~mm}$, conforme a NBR 13276 (ABNT, 2016) [28], para a carga máxima do ensaio de $1 \mathrm{kN}$, o deslocamento foi abaixo de $2 \mathrm{~mm}$ para as argamassas. Isto demonstra a alta consistência das argamassas, pouco adequadas para aplicação. A utilização de uma maior quantidade de água ou ainda o uso de aditivos auxiliaria na lubrificação, e consequentemente reduzindo as cargas de compressão. 


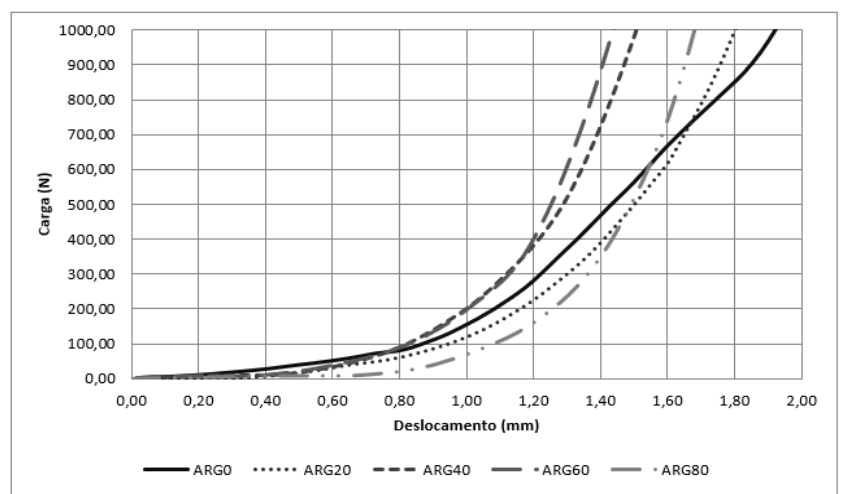

Figura 5: Squeeze-flow das argamassas sem (referência) e com escória BSSF (3 mm/s).

Destaca-se ainda que a argamassa de referência, que apresentou uma menor relação a/c, foi a que demonstrou o melhor comportamento entre as argamassas. O traço ARG80 apesar da maior quantidade de escória de aciaria BSSF, era esperado um menor deslocamento máximo, entretanto, possivelmente em virtude da maior relação a/c, pode ter ocasionado esse aumento no deslocamento máximo, tendo em vista que as medidas de índice de consistência por si só, não são suficientes para determinar o comportamento do material (CARDOSO et al, 2009) [45].

Cabe destacar ainda que valores baixos de deslocamentos máximos encontrados no ensaio do squeeze flow podem estar relacionados com a etapa de mistura, pois ao investigar diversos métodos de mistura, incluindo o preconizado pela NBR 13276:20016, França et al., (2013) [46] constataram que o referido procedimento de mistura, o mesmo adotado nesta pesquisa, atingiu menores valores de deslocamento, se comparados com os demais procedimentos, o que demonstra que esse procedimento não foi capaz de dispersar as partículas aglomeradas com eficiência, resultando em unidades móveis (aglomerados) maiores, o que dificulta o fluxo da argamassa.

Em adição, tem-se que todas as argamassas não apresentaram o estágio II (saltando do estágio I para o estágio III). As curvas mostram uma mudança de um estágio elástico diretamente para o strain hardening, fase III, o qual a carga aumenta consideravelmente, com pequeno acréscimo de deformação. O segundo estágio, ausente nas argamassas, relaciona-se com à deformação plástica do material, onde a argamassa é capaz de sofrer deformações sem aumento expressivo da força, o que torna um comportamento apropriado para aplicação e espalhamento da argamassa [32].

O crescimento exponencial das cargas caracteriza o enrijecimento por deformação, causado por altos níveis de atrito entre os agregados. Devido aos baixos teores de ar na argamassa, os agregados ficam muito próximos dificultando o fluxo do material. Por outro lado, o aumentando do teor de ar nas argamassas ocasiona um aumento no teor de pasta, mantendo os agregados distantes e lubrificados [47]. Com isto, as argamassas com elevado teor de ar apresentam comportamento predominantemente plástico, para os níveis de deformação impostos. As bolhas de ar aumentam o volume ocupado pela pasta e reduzem sua resistência, promovendo facilidade do fluxo, bem como do escorregamento dos grãos [32].

No mesmo sentido, o estudo realizado por Amancio (2019) [48], tambem foi constatado a redução do deslocamento máximo pelo squeeze-flow nas argamassas com escória de aciaria, o qual foi justificado pelo baixo teor de ar das argamassas, ausencia de aditivo, método de mistura e dimensão máxima caracteristica do agregado $(2,36 \mathrm{~mm})$.

\subsection{Estado endurecido}

A Tabela 6 apresenta a caracterização das argamassas quanto às propriedades mecânicas no estado endurecido.

Tabela 6: Propriedades mecânicas no estado Endurecido.

\begin{tabular}{|c|c|c|c|c|c|c|c|c|c|c|c|c|}
\hline \multirow{2}{*}{ Traço } & \multicolumn{3}{|c|}{$\begin{array}{c}\text { Resistência à } \\
\text { compressão (MPa) }\end{array}$} & \multicolumn{3}{|c|}{$\begin{array}{c}\text { Resistência à tração } \\
\text { na flexão (MPa) }\end{array}$} & \multicolumn{3}{|c|}{$\begin{array}{l}\text { Densidade de massa } \\
\qquad\left(\mathrm{kg} / \mathrm{m}^{3}\right)\end{array}$} & \multicolumn{3}{|c|}{$\begin{array}{c}\text { Módulo } \\
\text { dinâmico (GPa) }\end{array}$} \\
\hline & $\begin{array}{l}\text { Média } \\
(\mathrm{MPa})\end{array}$ & DP. & $\begin{array}{l}\mathrm{CV} \\
(\%)\end{array}$ & $\begin{array}{l}\text { Média } \\
(\mathrm{MPa})\end{array}$ & DP. & $\begin{array}{l}\mathrm{CV} \\
(\%)\end{array}$ & $\begin{array}{l}\text { Média } \\
(\mathrm{MPa})\end{array}$ & DP. & $\begin{array}{l}\mathrm{CV} \\
(\%)\end{array}$ & $\begin{array}{l}\text { Média } \\
(\mathrm{MPa})\end{array}$ & DP. & $\begin{array}{l}\mathrm{CV} \\
(\%)\end{array}$ \\
\hline ARG0 & 14,28 & 0,82 & 5,74 & 4,75 & 1,18 & 24,84 & 2,05 & 0,02 & 0,98 & 16,70 & 0,29 & 1,74 \\
\hline ARG20 & 15,88 & 0,89 & 5,61 & 4,67 & 0,25 & 5,35 & 2,11 & 0,03 & 1,42 & 22,50 & 1,21 & 5,38 \\
\hline ARG40 & 14,01 & 1,47 & 10,49 & 2,92 & 0,26 & 8,90 & 2,21 & 0,03 & 1,36 & 23,20 & 1,08 & 4,66 \\
\hline ARG60 & 13,19 & 1,38 & 10,46 & 4,20 & 0,31 & 7,38 & 2,21 & 0,02 & 0,91 & 24,10 & 2,22 & 9,21 \\
\hline ARG80 & 13,81 & 1,44 & 10,43 & 4,67 & 0,25 & 5,35 & 2,30 & 0,05 & 2,17 & 20,30 & 1,42 & 7,00 \\
\hline
\end{tabular}


A Figura 6 apresenta os valores de resistências médias à compressão e tração na flexão das argamassas. Quanto aos resultados de resistência à tração na flexão, com exceção do traço ARG40, os demais traços não existem diferenças significativas conforme o teste de Tukey de comparação de médias, apesar dos valores da relação a/c serem superiores aos do traço ARG0. Entretanto, cabe destacar que o resultado da resistencia à tração na flexão para o traço ARG40 não foi esperado, tendo em vista que os a mistura da argamassa, bem como os procedimentos de moldagem foram realizados no mesmo dia dos demais, bem como pelo mesmo operador.
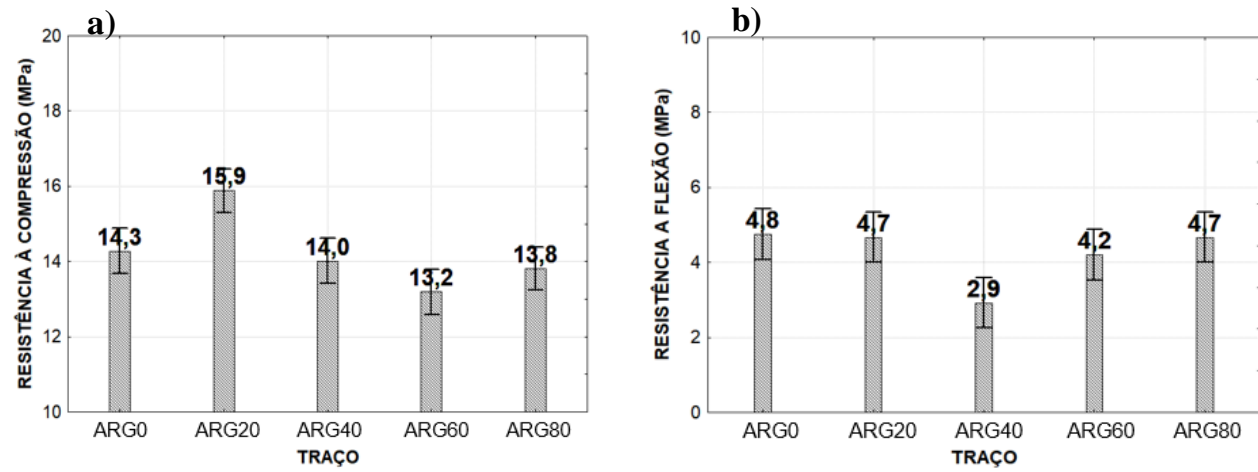

Figura 6: Resistência à compressão média (a) e tração na flexão (b) das argamassas com e sem escória de aciaria BSSF.

Já quanto a resistência à compressão, tem-se destaque para o traço ARG20, o que houve um aumento da resistência se comparado com o traço de referência, e ambos os traços apresentaram um baixo desvio padrão, menor que 0,90 , conforme Tabela 6 . Isso é justificado pela forma multi-angular do agregado de escória, levando a um melhor atrito entre partículas e matriz [38]. Para os demais teores de substituição de areia por escória, houve redução da resistência mecânica, pelo aumento mais elevado da relação a/c, fato também constatado de perda de resistência por Campos et al (2018) [39] utilizando escória de aciaria BSSF e Lacerda (2015) [49] ao utilizar escória de aciaria de forno elétrico a arco (FEA). Entretanto, conforme o teste de comparação de médias de Tukey, foi possível constatar que com exceção do traço ARG20, que apresentou um aumento significativo na resistência à compressão, para os demais traços não existem diferenças significativas.

Em adição ressalta-se que ocorre uma sobreposição de efeitos na resistência à compressão das argamassas, geradas pela relação a/c e pela massa unitária dos agregados. Por um lado, os traços com maiores teores de escória de aciaria BSSF, apresentam maiores valores de relação a/c, o que ocasiona uma redução na resistência. Por outro, o aumento do teor de substituição da areia natural por escória de aciaria, ocasiona um aumento da massa unitária da mistura referente à parcela do agregado, pois conforme Tabela 2, a massa unitária da escória de aciaria $\operatorname{BSSF}\left(2,08 \mathrm{~g} / \mathrm{cm}^{3}\right)$ é aproximadamente $48 \%$ superior à da areia natural $(1,48$ $\mathrm{g} / \mathrm{cm}^{3}$ ). Neste sentido, Carasek et al (2018) [50] explica que as resistências das argamassas (à compressão e à tração na flexão) e a massa unitária dos agregados podem ser correlacionadas por regressão linear crescente $(\mathrm{R}>0,8)$, ou seja, com o aumento da massa unitária ocasiona um aumento da resistência.

Os resultados de resistência potencial de aderência das argamassas são apresentados na Figura 7. Observou-se que as argamassas com maiores teores de escória, apresentaram valores inferiores ao da argamassa de referência. Entretanto, apesar do valor quantitativo da argamassa de referência ser superior as demais argamassas com escória, foi verificado por meio da ANOVA que a substituição da areia natural por escória não influencia significativamente nas propriedades de aderência das argamassas. $\mathrm{O}$ mesmo fato constatado por Santamaría-Vicario et al., 2015; Campos et al, 2018 [40, 41]. Isto pode ser justificado por inúmeros fatores, como a maior relação a/c das argamassas com escória de aciaria BSSF, menores valores de retenção de água, e baixo deslocamento obtido pelo ensaio do squeeze-flow. Informa-se ainda que o resultado do traço ARG40 foi inesperado, em virtude de ambos os traços de argamassas terem sidos realizados nas mesmas condições climáticas e pelo mesmo operador. 


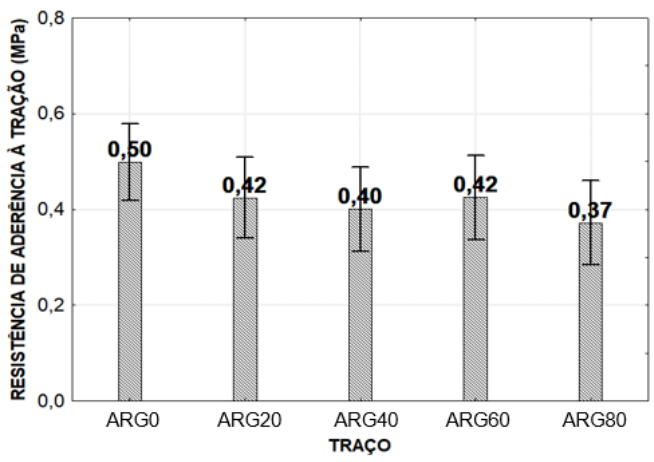

Figura 7: Resistência potencial de aderência à tração das argamassas.

Em relação ao fator a/c, o aumento do consumo de água reduz as propriedades mecânicas das argamassas, incluindo a resistência potencial de aderência a tração, fato também constatado por Silva; Campiteli (2008) [51] que constataram que o aumento da relação a/c das argamassas gera uma redução da resistência de aderência da argamassa. Quanto a retenção de água, as argamassas com escória de aciaria apresentaram menores valores de retenção de água (Tabela 5), o que afeta negativamente a aderência das argamassas, ao passo que a rápida perda de água da argamassa causa um comprometimento na sua aderência, resistência mecânica, capacidade de absorver deformações e consequentemente provoca perda da durabilidade e estanqueidade [52].

No mais, como as argamassas com escória de aciaria BSSF atingiram menores valores de deslocamento máximo na carga máxima do ensaio $(1 \mathrm{kN})$, isto pode influenciar negativamente na resistência potencial de aderência das argamassas. Silva et al. (2005) [53] explica que as argamassas trabalham em função da sua capacidade de fluir e de se deformar, quando submetida a uma determinada tensão de cisalhamento, apresentando um contato mais extenso com o substrato, otimizando o mecanismo de aderência.

Quanto ao módulo de elasticidade dinâmico (Tabela 6), as argamassas com escória tiveram valores superiores aos da argamassa de referência. Isto se deve possivelmente devido a massa específica da escória $\left(3,86 \mathrm{~g} / \mathrm{cm}^{3}\right)$ ser superior ao da areia natural $\left(2,59 \mathrm{~g} / \mathrm{cm}^{3}\right)$, com isto, tem-se um aumento da Velocidade de propagação de pulso ultrassônico, e consequentemente, o aumento do módulo de elasticidade dinâmico. CARRIJO [54], em estudo experimental constatou que concretos com agregados mais densos tendem a gerar concretos com maiores valores de módulo de elasticidade. Mesmo fato constatado por AMANCIO et al. [55] ao investigar diversos traços de argamassas com escória de aciaria BSSF.

Nota-se que para o traço ARG80, o valor de módulo de elasticidade dinâmico reduz, ocorrendo uma inversão dos demais valores. Isso se deve possivelmente em virtude do referido traço apresentar a maior relação a/c dos traços investigados, ao passo que conforme aumenta-se o consumo de água, aumenta-se a porosidade do material, e consequentemente, reduz-se a velocidade de propagação de pulso ultrassônico e o módulo de elasticidade dinâmico.

Os elevados valores de módulo de elasticidade dinâmico (Ed) de todas as argamassas pode ser justificado pelo baixo teor de ar das argamassas. As bolhas de ar aumentaram a capacidade de deformação da argamassa e reduziram sua rigidez [56]. Ao passo que conforme a Tabela 5, os valores de teor de ar ficaram compreendidos entre 1 e $5 \%$. Para argamassas de revestimento produzidas sem aditivos, seja argamassas simples ou mistas, o teor de ar geralmente encontra-se em torno de 2 a $5 \%$ do volume total [43] que vem de acordo com os resultados obtidos.

Os elevados valores de módulo de elasticidades podem afetar negativamente a durabilidade do revestimento, tendo em vista que quanto menor o valor do módulo, maior é a capacidade da argamassa absorver deformações [57, 58]. Com isto, os revestimentos com valores de módulo de elasticidade mais elevados são mais susceptíveis a sofrerem fissuração, o que afeta diretamente a a estanqueidade e consequentemente a vida útil do revestimento.

Conforme as recomendações do Centre Scientifique et Techinique de la Construction (CSTB) [59], o grau de fissurabilidade se classifica em Baixa Fissurabilidade (Ed $\leq 7,0 \mathrm{GPa})$, Média Fissurabilidade $(7,0$ $\mathrm{GPa} \leq \mathrm{Ed} \leq 12,0 \mathrm{GPa})$ e Alta Fissurabilidade $(\mathrm{Ed} \geq 12,0 \mathrm{GPa})$. Em consoante, a referida norma ainda traz a correlação entre o módulo de elasticidade dinâmico $(\mathrm{Ed})$ e a resistência à tração na flexão (ft) e o potencial de fissurabilidade, sendo $\mathrm{Ed} / \mathrm{ft} \leq 25,25<\mathrm{Ed} / \mathrm{ft}<35$ e $\mathrm{Ed} / \mathrm{ft}>35$, respectivamente para baixa, média e alta fissurabilidade, com isto, todas as argamassas têm alta fissurabilidade.

A Tabela 7 apresenta a caracterização das argamassas quanto às propriedades físicas no estado endurecido. 
Tabela 7: Propriedades físicas do concreto no estado Endurecido

\begin{tabular}{l|l|l|l|l|l|l|l|l|l}
\hline \multirow{2}{*}{ Traço } & \multicolumn{3}{|c|}{ Índice de vazios $(\%)$} & \multicolumn{3}{c|}{$\begin{array}{c}\text { Absorção de água total } \\
(\%)\end{array}$} & \multicolumn{3}{c}{$\begin{array}{c}\text { Coeficiente de capilaridade } \\
\left(\mathbf{g} / \mathbf{d m}^{2} . \mathbf{m i n}^{\mathbf{0}, 5}\right)\end{array}$} \\
\cline { 2 - 11 } & Média & DP. & CV & Média & DP. & CV & Média & DP. & CV \\
\hline ARG0 & 25,30 & 2,73 & 10,79 & 14,00 & 1,40 & 10,00 & 7,00 & 1,29 & 18,43 \\
\hline ARG20 & 25,40 & 0,37 & 1,46 & 13,00 & 0,24 & 1,85 & 7,00 & 0,46 & 6,57 \\
\hline ARG40 & 25,90 & 0,35 & 1,35 & 13,00 & 0,24 & 1,85 & 10,00 & 0,31 & 3,10 \\
\hline ARG60 & 26,00 & 0,30 & 1,34 & 12,00 & 0,19 & 1,58 & 8,00 & 1,75 & 21,88 \\
\hline ARG80 & 26,70 & 0,33 & 1,15 & 12,00 & 0,13 & 6,50 & 10,00 & 0,59 & 5,90 \\
\hline
\end{tabular}

O índice de vazios e o coeficiente de capilaridade das argamassas, foram maiores nas argamassas com escória de aciaria, possivelmente devido à maior relação a/c. $\mathrm{O}$ valor de vazios reflete os valores de resistência mecânica, no qual maiores índices de vazios tendem a gerar argamassas com menores valores de resistência à compressão.

Por fim, a Tabela 8 apresenta a classificação das argamassas conforme a NBR 13281 (ABNT, 2005) [60]. Constata-se que apesar da substituição da areia por escória nas argamassas alterar as propriedades no estado fresco e endurecido, com exceção da propriedade de retenção de água, todas as propriedades se enquadraram na mesma classe.

Tabela 8: Classificação das argamassas conforme NBR 13281:2005

\begin{tabular}{l|l|l|l|l|l|l|l}
\hline \multirow{2}{*}{ Traço } & $\begin{array}{l}\text { Resistência à } \\
\text { compressão }\end{array}$ & $\begin{array}{l}\text { Densidade } \\
\text { aparente } \\
\text { endurecido }\end{array}$ & $\begin{array}{l}\text { Resistência } \\
\text { à tração na } \\
\text { flexão }\end{array}$ & $\begin{array}{l}\text { Coeficiente de } \\
\text { capilaridade }\end{array}$ & $\begin{array}{l}\text { Densidade } \\
\text { aparente } \\
\text { fresco }\end{array}$ & $\begin{array}{l}\begin{array}{l}\text { Retenção } \\
\text { de água }\end{array} \\
\text { Resistência de } \\
\text { aderência }\end{array}$ \\
\cline { 2 - 8 } ARG0 & P6 & M6 & R6 & C5 & D6 & U5 & A3 \\
ARG20 & P6 & M6 & R6 & C5 & D6 & U3 & A3 \\
ARG40 & P6 & M6 & R5 & C5 & D6 & U3 & A3 \\
ARG60 & P6 & M6 & R6 & C5 & D6 & U3 & A3 \\
ARG80 & P6 & M6 & R6 & C5 & D3 & A3 \\
\hline
\end{tabular}

\section{CONCLUSÕES}

As argamassas com escória de aciaria BSSF são menos trabalháveis e demandam uma maior relação a/c para obter o mesmo espalhamento. Quanto ao comportamento reológico, as argamassas em estudo apresentaram baixo deslocamento, além de não apresentarem o estágio II na curva do squeeze-flow, sendo o traço de referência a que apresentou o melhor resultado.

Em relação a massa específica no estado fresco e endurecido das argamassas, verificou-se um incremento com o aumento o teor de escória, devido a maior massa específica do agregado. A retenção de água foi maior na argamassa de referência, sem escória de aciaria, possivelmente em virtude na menor relação a/c, o que melhora suas propriedades no estado endurecido. A argamassa de referência apresentou menor valor de módulo de elasticidade, coeficiente de capilaridade e índice de vazios, além de maior valor de resistência de aderência.

As argamassas com escória de aciaria BSSF apresentaram elevados valores de módulo de elasticidade dinâmica. Com isto, estas argamassas tendem a ser mais propensas a fissuração, em virtude da menor capacidade de sofrer deformação, sendo viável investigar o comportamento dessas argamassas com aditivos, como por exemplo, incorporador de ar.

Nesta pesquisa, para os materiais e metodologias adotadas, tem-se destaque para o teor de substituição de 20\%, o qual apresentou valores de resistência mecânica superiores ao da argamassa de referência. Nos ensaios de índice de vazios, capilaridade e absorção de água, o teor de $20 \%$ apresentou desempenho igual ou melhor que o traço de referência, favorecendo assim a durabilidade do revestimento. Em adição, destaca-se que com exceção da retenção de água, que foi inferior para o teor de $20 \%$ de substituição, se comparado com o traço de referência, as demais propriedades se enquadram na mesma classe proposta pela NBR 13281 (ABNT, 2005).

\section{AGRADECIMENTOS}

Os autores agradecem ao Programa de Pós-Graduação em Engenharia Civil: Estruturas e Construção Civil (PEC) e ao Laboratório de Materiais e Construção Civil (LMCC) da Universidade Federal do Ceará - UFC. 


\section{BIBLIOGRAFIA}

[1] BERNDT, WORDSTEEL ASSOCIATION. World steel in figures 2018. Belgium. ISBN: 978-2-93006989-0. Disponível em: https://www.worldsteel.org/en/dam/jcr:f9359dff-9546-4d6b-bed0996201185b12/World+Steel+in+Figures+2018.pdf. Acesso em 10 de janeiro, 2019.

[2] QASRAWI, H. The use of steel slag aggregate to enhance the mechanical properties of recycled aggregate concrete and retain the environment. Construction and Building Materials v. 54 pp. 298-304, 2014. [3] IABr. (2016). Relatório de Sustentabilidade. Fonte: Instituto Aço Brasil: Disponível em: <http://www.acobrasil.org.br/sustentabilidade/

[4] SOUZA, T.V.P. Caracterização de escória de conversor a oxigênio obtida no processo BSSF antes $e$ após tratamento hidrometalúrgico. 2016. 62 f. Dissertação (Mestrado em Ciência de Materiais) - Centro de Tecnologia, Universidade Federal do Ceará, Fortaleza, 2016.

[5] LIU, Y., WANG, X. Application of the BSSF molten steel slag processing technology in POSCO. Baosteel Technical Research; Shanghai. v. 5, ed. 2, pp. 20-23, 2011.

[6] LI, G., GUO, M. Current Development of Slag Valorisation in China. Waste Biomass Valor, v. 5, pp. 317-325, 2014.

[7] LOHANI, T.K., PADHI, M., DASH, K. P., et al. Optimum utilization of quarry dust as partial replacement of sand in concrete. Internacional Journal of Applied Sciences and Engineering Research, v. 1, n. 2, pp. $391-404,2012$.

[8] BRITO, P.D., VEIGA, J.R. Mortars Made with Fine Granulate from Shredded Tires. Journal of Materials in Civil Engineering. V. 25(4), pp. 519-529, 2013

[9] CHAVES, M.A., SANTOS, B.E. Uso de imagens CBERS na identificação de áreas de extração de areia na Região Metropolitana de Salvador - BA XIII Simpósio Brasileiro de Sensoriamento Remoto, Florianópolis, Brasil, 21 a 26 abril de 2007. INPE.

[10] TOKARSKI, R.B., MATOSKI, A., CECHIN, L., et al., Comportamento das argamassas de revestimento no estado fresco, compostas com areia de britagem de rocha calcária e areia natural. Matéria (Rio J.) [online]. 2018 , v.23, n.3

[11] PIMENTEL, L.L., PISSOLATO JUNIOR, O., JACINTHO, A.E.P.G.A., et al., Argamassa com areia proveniente da britagem de resíduo de construção civil - Avaliação de características físicas e mecânicas. Matéria (Rio J.) [online]. 2018, v.23, n.1

[12] KURZ, M.N., BRANDELli, T.M., PALIGA, C.M., et al., A potencialidade do uso de resíduo de borracha de pneu em argamassa: análise das propriedades físicas e mecânicas. Matéria (Rio J.) [online]. 2018 , v.23, n.3

[13] TRENTIN, P.O., et al. Substituição parcial de agregado miúdo por resíduo de vidro moído na produção de argamassa. Matéria (Rio J.) [online]. 2020, v.25, n.1

[14] RIBEIRO, U.G., SANTOS, D.F. Physical-mechanical potential properties of wastes from glass lapping to produce mortar as partial replacement of the conventional aggregate. Rev. IBRACON Estrut. Mater. [online]. 2020, v.13, n.1

[15] SOUZA, N.S.L., et al. Desenvolvimento de agregados leves a partir de resíduo de corte de pedras ornamentais (granitos e mármores) e argila. Matéria (Rio J.) [online]. 2020, v.25, n.1

[16] BUSELATTO, D.M., et al. Incorporação de lodo de estação de tratamento de água (ETA) como agregado miúdo em concretos: avaliação das propriedades físico-mecânicas. Matéria (Rio J.) [online]. 2019, v. 24, n. 1

[17] SOUZA, M.M., et al. Uso do lodo de esgoto na produção de agregados leves: uma revisão sistemática de literatura. Matéria (Rio J.) [online]. 2020, v. 25, n.1

[18] ASSOCIAÇÃO BRASILEIRA DE NORMAS TÉCNICAS. NBR NM 248: Agregados - Determinação da composição granulométrica. Rio de Janeiro, 2003.

[19] ASSOCIAÇÃO BRASILEIRA DE NORMAS TÉCNICAS. NBR 7211. Agregados para concreto Especificação, Rio de Janeiro, 2009.

[20] ASSOCIAÇÃO BRASILEIRA DE NORMAS TÉCNICAS. NBR NM 45: Agregados - Determinação da massa unitária e do volume de vazios. Rio de Janeiro, 2006.

[21] ASSOCIAÇÃO BRASILEIRA DE NORMAS TÉCNICAS. NBR NM 52. Agregado miúdo Determinação da massa específica e massa específica aparente. Rio de Janeiro, 2009

[22] AL ROUSAN, T.M. (2004) Characterization of Aggregate Shape Properties Using a Computer Automated System. 2004. 211 f. Tese (Doutorado em Engenharia Civil), Office of Graduate Studies, Texas A\&M University, Texas, 2004.

[23] ASSOCIAÇÃO BRASILEIRA DE NORMAS TÉCNICAS. NBR 5752: Materiais pozolânicos Determinação do índice de desempenho com cimento Portland aos 28 dias. Rio de Janeiro, 2014

[24] ASSOCIAÇÃO BRASILEIRA DE NORMAS TÉCNICAS. NBR 12653: Materiais pozolânicos Requisitos. Rio de Janeiro, 2014, versão corrigida 2015. 
[25] ASSOCIAÇÃO BRASILEIRA DE NORMAS TÉCNICAS. NBR 11582: Cimento Portland Determinação da expansibilidade Le Chatelier. Rio de Janeiro, 2016.

[26] MASUERO, A.B. Estabilização das escórias de aciaria elétrica com vistas a sua utilização como substituição ao cimento. Tese (Doutorado em Engenharia), Programa de Pós-Graduação em Engenharia de Minas, Metalurgia e dos Materiais, Universidade Federal do Rio Grande do Sul, 2001.

[27] ASSOCIAÇÃO BRASILEIRA DE NORMAS TÉCNICAS. NBR 16541: Argamassa para assentamento e revestimento de paredes e tetos - Preparo da mistura para a realização de ensaios. Rio de Janeiro, 2016

[28] ASSOCIAÇÃ̃O BRASILEIRA DE NORMAS TÉCNICAS. NBR 13276: Argamassa para assentamento e revestimento de paredes e tetos - Preparo da mistura e determinação do índice de consistência. Rio de Janeiro, 2005.

[29] ASSOCIAÇÃO BRASILEIRA DE NORMAS TÉCNICAS. NBR 13278: Determinação da densidade de massa e do teor de ar incorporado. Rio de Janeiro, 2005.

[30] ASSOCIAÇÃO BRASILEIRA DE NORMAS TÉCNICAS. NBR 13277: Argamassa para assentamento e revestimento de paredes e tetos - Determinação da retenção de água. Rio de Janeiro, 2005.

[31] ASSOCIAÇÃO BRASILEIRA DE NORMAS TÉCNICAS. NBR 15839: Argamassa de assentamento e revestimento de paredes e tetos - Caracterização reológica pelo método squeeze-flow. Rio de Janeiro, 2010.

[32] CARDOSO, F.A., PILEGGI, R.G., JOHN, V.M. Caracterização reológica de argamassas pelo método de squeeze-flow. VI Simpósio Brasileiro de Tecnologia de Argamassas. Florianópolis, 23 a 25 de maio de 2005

[33] ASSOCIAÇÃO BRASILEIRA DE NORMAS TÉCNICAS. NBR 13279: Argamassa para assentamento e revestimento de paredes e tetos - Determinação da resistência à tração na flexão e à compressão. Rio de Janeiro, 2005.

[34] ASSOCIAÇÃO BRASILEIRA DE NORMAS TÉCNICAS. NBR 15630: Argamassa para assentamento e revestimento de paredes e tetos - Determinação do módulo de elasticidade dinâmico através da propagação de onda ultrassônica. Rio de Janeiro, 2009.

[35] ASSOCIAÇÃO BRASILEIRA DE NORMAS TÉCNICAS. NBR 13280: Argamassa para assentamento e revestimento de paredes e tetos - determinação da densidade de massa aparente no estado endurecido. Rio de Janeiro, 2005.

[36] ASSOCIAÇÃO BRASILEIRA DE NORMAS TÉCNICAS. NBR 15259: Argamassa para assentamento e revestimento de paredes e tetos - Determinação da absorção de água por capilaridade e do coeficiente de capilaridade. Rio de Janeiro, 2005.

[37] ASSOCIAÇÃO BRASILEIRA DE NORMAS TÉCNICAS. NBR 9778: Argamassa e concreto endurecidos - Determinação da absorção de água, índice de vazios e massa específica. Rio de Janeiro, 2009.

[38] ASSOCIAÇÃO BRASILEIRA DE NORMAS TÉCNICAS. NBR 13528: Revestimento de paredes e tetos de argamassas inorgânicas - Determinação da resistência de aderência à tração. Rio de Janeiro, 2010.

[39] LE, D.H., SHEEN,Y.N., BUI, Q.B. An assessment on volume stabilization of mortar with stainless steel slag sand. Construction and Building Materials v.155, pp. 200-208, 2017.

[40] CAMPOS, S.A., RAFAEL, M.F.C., CABRAL, A.E.B. Evaluation of steel slag of Companhia Siderúrgica do Pecém replacing fine aggregate on mortars. Procedia Structural Integrity, v. 11, p. 145-152, 2018.

[41] SANTAMARÍA-VICARIO, I., RODRÍGUEZ, A., GONZÁLEZ,S.G., et al., Design of masonry mortars fabricated concurrently with diferent steel slag aggregates. Construction and Building Materials. v. 95 p. 197-206, 2015

[42] SANTAMARÍA-VICARIO, I., RODRÍGUEZ, A., GONZÁLEZ, S.G., et al., Durability behavior of steelmaking slag masonry mortars. Materials and design, v. 97, pp. 307-315, 2016.

[43] DO Ó, S.W. Análise da retenção de água em argamassas de revestimento aditivadas. Dissertação (Mestrado em Engenharia Civil). Universidade de Brasilia. Faculdade de Tecnologia. Brasilia, DF, Brasil, 2004.

[44] INCE, C., CARTER, A., WILSON, M.A., et al., Factors affecting the water retaining characteristics of limeand cement mortars in the freshly-mixed state. Materials and Structures, v. 44, pp. 509-516, 2011.

[45] CARDOSO, F.A., JOHN, V.M., PILEGGI, R.G. Rheological behavior of mortars under different squeezing rates. Cement and concrete research, v. 39, n. 9, pp. 748-753, 2009.

[46] FRANÇA, M.S., CARDOSO, F.A., PILEGGI, R.G. Influence of laboratory mixing procedure on the properties of mortars. Ambiente construído, Porto Alegre, v. 13, n. 2, pp. 111-124, 2013.

[47] CARDOSO, F.A., CAMPORA, F.L., PILEGGI, R.G., et al., Caracterização reológica de argamassas do mercado por squeeze-flow. VII Simpósio Brasileiro de Tecnologia de Argamassas. Anais... Pernambuco, Recife, 2007.

[48] AMANCIO, F.A. Estudo de propriedades no estado fresco de argamassas de revestimento com escória de aciaria BSSF. Dissertação (mestrado). Programa de Pós graduação em Engenharia Civil: Estruturas e Construção Civil. Universidade Federal do Ceará, Fortaleza, 2019, 85p. 
[49] LACERDA, C. Traços de argamassa utilizando escória de aciaria elétrica. Dissertação (Mestrado) UniFOA / Mestrado Profissional em Materiais, Volta Redonda: UniFOA, 2015. 70 p.

[50] CARASEK, H., GIRARDI, A.C.C., ARAÚJO, R.C., et al., Estudo e avaliação de agregados reciclados de resíduo de construção e demolição para argamassas de assentamento e de revestimento. Cerâmica, v. 64, pp. 288-300, 2018.

[51] SILVA, N.G., CAMPITELI, V.C. Correlação entre módulo de elasticidade dinâmico e resistências mecânicas de argamassas de cimento, cal e areia. Ambiente Construído, Porto Alegre, v. 8, n. 4, pp. 21-35, out./dez. 2008.

[52] BAÍA, L.L.M., SABBATINI, F.H. Projeto e execução de revestimento de argamassa. 4. ed. São Paulo, SP. O Nome da Rosa 2008, 88p.

[53] SILVA, R.P., BARROS, MERCIA, M.S.B., et al., 2005. Avaliação do comportamento da argamassa no estado fresco através dos métodos de mesa de consistência, dropping ball e squeeze flow. In: Simpósio brasileiro de tecnologia de argamassas, 6, 2005, Fortaleza. Anais...Florianópolis, 2005, p.1-10.

[54] CARRIJO, P.M. Análise da influência da massa específica de agregados graúdos provenientes de resíduos de construção e demolição no desempenho mecânico do concreto. Tese de M.Sc., Politécnica da Universidade de São Paulo, Departamento de Engenharia de Construção Civil, São Paulo, SP, Brasil, 2005 [55] AMANCIO, F.A. et al. Propriedades mecânicas de argamassas com substituição da areia natural por escória de aciaria BSSF (baosteel's slag short flow). Matéria (Rio J.), Rio de Janeiro , v. 25, n. 1, e$12562,2020$.

[56] HADDAD, L.D., COSTA, C.M., LOPES, P.H.P., et al., Análise da influência da granulometria do agregado miúdo nas propriedades mecânicas e de durabilidade das argamassas de revestimento. Ciência \& Engenharia. v. 25, n. 1, pp. 07-16, jan.-jun. 2016.

[57] SILVA, N.G. Argamassa de Revestimento de Cimento, Cal e Areia Britada de Rocha Calcária. Dissertação de M. Sc., Universidade Federal do Paraná, Curitiba, PR, Brasil, 2006.

[58] NAKAKURA, E.H., CINCOTTO, M.A. Análise dos requisitos de classificação de argamassas de assentamento e revestimento. In: BT/PCC/359 - Boletim Técnico da Escola Politécnica da USP, Departamento de Engenharia de Construção, São Paulo, 2004

[59] CSTC - CENTRE SCIENTIFIQUE ET TECHNIQUE DE LA CONSTRUCTION. Hydrofuges de surface: choix et mise em oeuvre. Bruxelles, 1982. 24 p. (Note D`Information Technique - NIT n. 140)

[60] ASSOCIAÇÃO BRASILEIRA DE NORMAS TÉCNICAS. NBR 13281: Argamassa para assentamento e revestimento de paredes e tetos - Requisitos. Rio de Janeiro.

\section{ORCID}

Felipe Alves Amancio Alisson Rodrigues de Oliveira Dias

Douglas Alexandre Lima

Antônio Eduardo Bezerra Cabral
https://orcid.org/0000-0002-1349-683X

https://orcid.org/0000-0002-9892-6834

https://orcid.org/0000-0003-0671-4920

https://orcid.org/0000-0001-6394-1164 